\title{
Premorbid expertise produces category-specific impairment in a domain-general semantic disorder
}

\author{
Elizabeth Jefferies $^{\mathrm{a}, *}$, Timothy T. Rogers ${ }^{\mathrm{b}}$, Matthew A. Lambon Ralph ${ }^{\mathrm{c}}$ \\ a Department of Psychology, University of York, York, YO10 5DD, UK \\ ${ }^{\mathrm{b}}$ University of Wisconsin-Madison, USA \\ c University of Manchester, UK
}

\section{A R T I C L E I N F O}

\section{Article history:}

Received 23 March 2011

Received in revised form 29 June 2011

Accepted 19 July 2011

Available online 26 July 2011

\section{Keywords:}

Semantic dementia

Expertise

Category-specific

Individual differences

Semantic memory

Anterior temporal lobe

\begin{abstract}
A B S T R A C T
For decades, category-specific semantic impairment - i.e., better comprehension of items from one semantic category than another - has been the driving force behind many claims about the organisation of conceptual knowledge in the brain. Double dissociations between patients with category-specific disorders are widely interpreted as showing that different conceptual domains are necessarily supported by functionally independent systems. We show that, to the contrary, even strong or classical dissociations can also arise from individual differences in premorbid expertise. We examined two patients with global and progressive semantic degradation who, unusually, had known areas of premorbid expertise. Patient 1, a former automotive worker, showed selective preservation of car knowledge, whereas Patient 2 , a former botanist, showed selective preservation of information about plants. In non-expert domains, these patients showed the typical pattern: i.e., an inability to differentiate between highly similar concepts (e.g., rose and daisy), but retention of broader distinctions (e.g., between rose and cat). Parallel distributed processing (PDP) models of semantic cognition show that expertise in a particular domain increases the differentiation of specific-level concepts, such that the semantic distance between these items resembles non-expert basic-level distinctions. We propose that these structural changes interact with global semantic degradation, particularly when expert knowledge is acquired early and when exposure to expert concepts continues during disease progression. Therefore, category-specific semantic impairment can arise from at least two distinct mechanisms: damage to representations that are critical for a particular category (e.g., knowledge of hand shape and action for the category 'tools') and differences in premorbid experience.
\end{abstract}

(c) 2011 Elsevier Ltd. All rights reserved.

\section{Introduction}

A key objective of cognitive neuroscience is to understand the functional and neural organisation of semantic memory, which encompasses the meanings of words, pictures, objects, faces and facts about the world. One dominant view is that our semantic knowledge draws, at least in part, on sensory and motor representations (e.g., Barsalou, 1999; Martin, 2007; Pulvermuller, 2005). According to this theory, the meaning of an item like "hammer" is derived from links between neural assemblies that represent this object's distinctive shape, the "bang" sound that it makes, information about how you hold and use a hammer, linguistic properties of the word "hammer" and so on. In addition, some researchers propose that these sensory and motor features are combined to form amodal semantic representations in anterior temporal lobes (i.e.,

\footnotetext{
* Corresponding author. Tel.: +44 01904434368.

E-mail addresses: beth.jefferies@york.ac.uk, ej514@york.ac.uk(E. Jefferies).
}

there is an ATL "hub" which draws on modality-specific "spokes"; Patterson, Nestor, \& Rogers, 2007).

Patients who show category-specific semantic impairment i.e., differential loss of knowledge for one semantic category over another - are considered to be critical in understanding how the brain represents semantic information because they are thought to provide evidence that different domains of knowledge are differentially reliant on separate brain areas (reviewed in Capitani, Laiacona, Mahon, \& Caramazza, 2003). Double dissociations between patients on the same semantic tests (e.g., patient A's knowledge of animals is much worse than his knowledge of manmade objects, while patient B shows the opposite pattern) are particularly provocative, as they imply that category effects are not merely a consequence of the vulnerability of different tasks or semantic domains to damage (Mahon \& Caramazza, 2009; Shallice, 1988).

Over the last two decades, there have been over 125 published cases of category-specific impairment (Capitani et al., 2003), including a number of classical or strong double-dissociations, 
leading some researchers to conclude that conceptual knowledge is supported by a number of independent and anatomically segregated domain-specific modules formed over the course of human evolution. For instance, Caramazza and colleagues have proposed independent cortical modules supporting knowledge of animals, foods, tools, body parts, and conspecifics (Caramazza \& Shelton, 1998; Mahon \& Caramazza, 2009). These conclusions have, however, been the source of heated controversy, and a variety of alternative explanations of category-specific patterns of impairment have been advanced in the literature (Damasio, Tranel, Grabowski, Adolphs, \& Damasio, 2004; Farah \& McClelland, 1991; Humphreys \& Forde, 2001; Lambon Ralph, Lowe, \& Rogers, 2007; Martin \& Chao, 2001; Martin, Wiggs, Ungerleider, \& Haxby, 1996; Moore \& Price, 1999; Perani, Schnur, Tettamanti, Gorno-Tempini, Cappa, \& Fazio, 1999; Warrington \& McCarthy, 1987; Warrington \& Shallice, 1984). Different categories of knowledge might be differentially reliant on specific sensory and motor features which can be damaged independently: discriminating between animals might involve occipital-temporal areas involved in the processing of complex and highly overlapping visual forms, whereas knowledge of tools might conceivably draw on temporo-parietal and premotor areas involved in representing actions (Chao, Haxby, \& Martin, 1999; Martin \& Chao, 2001; Martin et al., 1996; Moore \& Price, 1999; Perani et al., 1999; Pobric, Jefferies, \& Lambon Ralph, 2010; Vitali, Abutalebi, Tettamanti, Rowe, Scifo, \& Fazio, 2005; Warrington \& McCarthy, 1987; Warrington \& Shallice, 1984). In line with this proposal, patients who have specific difficulty with animals often have damage to inferior temporal regions, whereas patients with poor knowledge of tools typically have damage affecting posterior middle temporal cortex/temporal-parietal junction or premotor cortex (Damasio, Grabowski, Tranel, Hichwa, \& Damasio, 1996; Damasio et al., 2004; Gainotti, Silveri, Daniele, \& Giustolisi, 1995; Tranel, Damasio, \& Damasio, 1997).

One reason for the continued controversy is that categoryspecific semantic impairment is relatively rare and investigations of this phenomenon rely to a large extent on single case studies. According to conventional wisdom, two individual cases showing an unusual and strong double-dissociation between two domains provides evidence that the dissociated domains are supported by functionally independent cognitive systems, even if, in the majority of cases, deficits in the two domains tend to co-occur (Coltheart, 2004; Shallice, 1988). This strong reliance on double dissociations exemplified by individual cases is, however, potentially problematic, because it is not clear which dissociations genuinely reflect the effects of brain-damage on functionally independent cognitive systems, and which arise as the consequence of important individual differences in premorbid knowledge about the dissociated domains.

Studies of healthy subjects certainly suggest that there can be considerable individual variation in knowledge of different categories, reflecting differential exposure to items from these domains (Funnell \& De Mornay Davies, 1996; Gauthier, Skudlarski, Gore, \& Anderson, 2000; Medin, Lynch, Coley, \& Atran, 1997; Tanaka \& Taylor, 1991). Moreover, there are significant differences between males and females in their knowledge of animals, foods and praxic objects (Albanese, Capitani, Barbarotto, \& Laiacona, 2000; Barbarotto, Laiacona, Macchi, \& Capitani, 2002). For these reasons, researchers place special emphasis on classical and strong dissociations, in which knowledge of one domain is within or only slightly below the normal range for age- and education-matched controls, while knowledge of another is substantially impaired (Shallice, 1988). Trend dissociations (in which both domains are substantially impaired although one more than another) are considered to be less powerful evidence of neural specialisation as they can more readily result from individual differences in background knowledge.
However, there is little evidence testifying to the validity of the individual difference assumption and, although there is evidence that a person's premorbid cognitive state can influence what happens in pathology (e.g., Snowdon, Lemper, Mortimer, Greiner, Wekstein, \& Markesbery, 1996; Wilson, Mendes de Leon, Barnes, Schneider, Bienias, \& Evans, 2002), this work has not focused on the question of whether premorbid differences in knowledge about different semantic domains might produce category-specific patterns of impairment. This is at least in part because a confluence of two unusual situations needs to occur: patients must have both a selective semantic impairment and also a known pre-morbid expertise in a specific field. We had a rare opportunity to study two patients with progressive semantic degradation associated with cortical atrophy within ATL, who were known to have expert knowledge pre-morbidly for cars and plants respectively. This allowed us to directly examine the extent to which category-specific semantic deficits can result from individual differences in patients' experience of different domains. One of these patients showed a profile consistent with semantic dementia (SD) - i.e., a highly specific and progressive deterioration of conceptual knowledge that largely spared other cognitive functions (Hodges, Patterson, Oxbury, \& Funnell, 1992; Snowden, Goulding, \& Neary, 1989). The other showed semantic degradation accompanied by other cognitive and language deficits.

SD patients have atrophy and hypometabolism focussed on the inferior aspects of the anterior temporal lobes (ATL) bilaterally, and the extent of this atrophy correlates with the severity of the semantic impairment (Galton, Patterson, Graham, Lambon-Ralph, Williams, \& Antoun, 2001; Mion, Patterson, Acosta-Cabronero, Pengas, Izquierdo-Garcia, \& Hong, 2010; Mummery, Patterson, Price, Ashburner, Frackowiak, \& Hodges, 2000; Nestor, Fryer, \& Hodges, 2006). The semantic impairment in SD is all encompassing: it affects the comprehension of items presented in every modality - including spoken and written words, pictures, environmental sounds, smells and touch (Bozeat, Lambon Ralph, Patterson, Garrard, \& Hodges, 2000; Coccia, Bartolini, Luzzi, Provinciali, \& Lambon Ralph, 2004; Luzzi, Snowden, Neary, Coccia, Provinciali, \& Lambon Ralph, 2007). Moreover, as would be expected from the theory that the ATL forms a central, amodal semantic "hub", patients show comparable levels of difficulty for all conceptual domains - living, manmade, concrete, abstract, nouns, verbs, etc. - so long as confounding factors, such as the frequency/familiarity of items and the specificity with which they must be classified, are controlled (Bird, Lambon Ralph, Patterson, \& Hodges, 2000; Jefferies, Patterson, Jones, \& Lambon Ralph, 2009; Lambon Ralph et al., 2007; Lambon Ralph, Patterson, Garrard, \& Hodges, 2003). Individual SD cases can occasionally show better comprehension for either living or non-living things in particular tasks, but of forty or so SD patients studied in Cambridge (UK), only one showed a significant category effect across a range of tasks (Lambon Ralph et al., 2003). The only consistent exception to this global semantic impairment seems to be number concepts, which presumably draw upon magnitude meanings that are independent of the ATL (Butterworth, Cappelletti, \& Kopelman, 2001; Jefferies, Bateman, \& Lambon Ralph, 2005).

SD thus provides the opportunity of studying the effects of premorbid expertise on impaired semantic cognition in a disorder that is associated with a global semantic impairment. Of particular interest is the question of whether such premorbid differences can lead to classical or strong double-dissociations between different conceptual domains. Prior work in this vein has led to somewhat contradictory findings. Robinson and Cipolotti (2001) described a professional artist with SD who was better at naming colours than objects, even when the colour terms were low frequency (e.g., turquoise). Omar, Hailstone, Warren, Crutch, and Warren (2010) studied a professional trumpeter with SD, who retained the abil- 
ity to recognise musical notation to the same degree as an expert control group; however, he showed mild impairment of the ability to complete a famous tune, severe deficits in naming the same tunes and poor identification of musical instruments from sound. In addition, Graham, Patterson, Pratt, and Hodges (1999b) found that a retired surgeon who developed SD was unable to name any surgical implements, although these were not directly compared with non-expert concepts at the specific-level. Similarly, two SD patients who had been skilled golf/bowls players showed considerable deterioration of their knowledge of these sports, although they retained considerable procedural knowledge and continued to play (Graham, Lambon Ralph, \& Hodges, 1997).

Here, for the first time, we examine whether differential exposure to different domains of knowledge can give rise to category-specific semantic impairment in the context of global semantic degeneration. We studied a patient with SD who had expert knowledge pre-morbidly for cars following his work as a production manager in the automotive industry. We compared him with a second patient with a progressive loss of semantic knowledge who was a retired plant scientist. We compared their knowledge of cars, plants and other concepts at the basic and specific levels, in order to adjudicate between various hypotheses about the fate of expert knowledge in the face of global semantic degradation. If expertise does not have a substantial influence on the degradation of semantic knowledge, judgements at the specific-level within both expert and non-expert domains should deteriorate more rapidly than basic-level judgements. This is because fine-grained semantic features are typically lost earlier than coarser distinctions in SD (Hodges, Graham, \& Patterson, 1995; Rogers, Lambon Ralph, Garrard, Bozeat, McClelland, \& Hodges, 2004). Alternatively, expertise might help to protect conceptual knowledge in these patients-for example, by encouraging the differentiation of highly similar concepts in semantic space (Rogers \& McClelland, 2004). If so, specific-level expert knowledge should be better preserved than specific-level non-expert knowledge: it might degrade more slowly and broadly in parallel with basic-level non-expert knowledge. Finally, there may be additional factors that benefit the retention of expert knowledge. For example, patients may encounter concepts from the expert domain more frequently, or from an earlier age, and this exposure may be ongoing during the course of the disease. Consequently, expert information might deteriorate at a slower rate than non-expert concepts at both the basic and specific level. This final scenario makes the striking prediction that patients may perform specific-level judgements within the expert domain more accurately than basic-level judgements within the non-expert domain.

To anticipate, we found that expertise increased the robustness of knowledge to semantic degradation, producing a classical double dissociation between car and plant tasks when patients were compared to age- and gender-matched controls. Thus, it appears that category-specific classical dissociations can arise from differences in premorbid experience, as well as from damage to representations of sensory or motor features that are critical for concepts within a particular category.

\section{Methods}

\subsection{Participants}

\subsubsection{Patients}

This work was approved by the local health authority ethics committee and informed consent was obtained. Both patients showed fluent speech characterised by severe word-finding difficulties, poor confrontational naming, impaired comprehension of words and pictures and surface dyslexia in reading aloud. In contrast, other cognitive functions, including day-to-day memory, were relatively well preserved. Patient 1 (car expert) fully met the criteria for SD: he showed a remarkably selective disorder of semantic memory - phonology, syntax, visual-spatial abilities and non-verbal reasoning were all spared. In picture naming, he made coordinate
Table 1

Demographic details and background neuropsychological assessments for 1 (car expert) and 2 (plant expert).

\begin{tabular}{|c|c|c|c|c|}
\hline & & Maximum & Patient 1 & Patient 2 \\
\hline Age & & & 50 & 67 \\
\hline Years of education & & & 11 & 19 \\
\hline Years since onset & & & 2 & 5 \\
\hline \multirow[t]{5}{*}{ Semantic } & Picture naming & 64 & $13^{\mathrm{a}}$ & $5^{a}$ \\
\hline & $\begin{array}{l}\text { Word-picture } \\
\text { matching }\end{array}$ & 64 & $32^{\mathrm{a}}$ & $51^{\mathrm{a}}$ \\
\hline & $\begin{array}{l}\text { Camel and Cactus } \\
\text { test: pictures }\end{array}$ & 64 & $32^{\mathrm{a}}$ & $45^{\mathrm{a}}$ \\
\hline & $\begin{array}{l}\text { Camel and Cactus } \\
\text { test: words }\end{array}$ & 64 & $27^{a}$ & $27^{\mathrm{a}}$ \\
\hline & $\begin{array}{l}\text { Synonym } \\
\text { judgement }\end{array}$ & 96 & $63^{a}$ & $63^{a}$ \\
\hline \multirow[t]{9}{*}{ Non-semantic } & Digit span & - & 7 & 3 \\
\hline & $\begin{array}{l}\text { PALPA word } \\
\text { repetition }\end{array}$ & 80 & 78 & $55^{\mathrm{a}}$ \\
\hline & $\begin{array}{l}\text { PALPA nonword } \\
\text { repetition }\end{array}$ & 30 & 29 & 14 \\
\hline & VOSP: dot counting & 10 & 10 & 10 \\
\hline & $\begin{array}{l}\text { VOSP: position } \\
\text { discrimination }\end{array}$ & 20 & 20 & 19 \\
\hline & $\begin{array}{l}\text { VOSP: number } \\
\text { location }\end{array}$ & 10 & 9 & 8 \\
\hline & $\begin{array}{l}\text { VOSP: cube } \\
\text { analysis }\end{array}$ & 10 & 10 & 8 \\
\hline & Rey figure copy & 36 & 35 & $31^{\mathrm{a}}$ \\
\hline & $\begin{array}{l}\text { Coloured } \\
\text { progressive } \\
\text { matrices }\end{array}$ & 36 & 33 & 29 \\
\hline
\end{tabular}

VOSP = Visual Object and Space Perception battery (Warrington \& James, 1991). Non-verbal reasoning assessed using the Coloured Progressive Matrices test (Raven, 1962).

${ }^{\text {a }}$ Impaired performance for Patient 1 (car expert) and Patient 2 (plant expert).

and superordinate semantic errors, descriptive responses and omissions. Patient 2 (plant expert) had greater difficulty with word production and repetition/digit span, and showed mild weakness on tests of visual-spatial functioning and nonverbal reasoning (see Table 1 ). His picture naming was particularly impaired given his word-picture-matching performance: the majority of his errors were omissions (71\%), with a smaller number of coordinate semantic errors (14\%). Two errors (3.4\%) were phonological in nature (e.g., "A bassit" for basket). This more mixed presentation is not completely consistent with a diagnosis of $\mathrm{SD}$ and might suggest a different pathology. MRI for both patients revealed atrophy of the inferior and lateral aspects of the ATL bilaterally (Fig. 1), consistent with their semantic impairment. Patient 2 showed additional atrophy in perisylvian cortex, in line with his additional language problems. The results of background neuropsychological assessments are shown in Table 1.

Patient 1 (car expert) professed an interest in cars from an early age. He worked for thirty years in a factory producing safety glass for the automotive industry which required familiarity with the makes and models of cars. He retired due to ill-health two years previously. He was still interested in cars at the time of the study and retained a collection of classic car magazines. He was also still driving and successfully passed a driving test during the investigation. He had little interest in plants/gardening. On a five-point scale ( 1 = very knowledgeable, $3=$ average level of knowledge and $5=$ not at all knowledgeable), he and his wife rated his pre-morbid knowledge of cars as 1 and plants as 5 .

Patient 2 (plant expert) had had a distinguished career as a Professor of Plant Sciences and his wife indicated that he had been interested in plants since he was a boy. His research over more than 30 years focussed on the factors affecting plant growth and crop yields. He retired due to ill health four years before the study but remained a keen gardener. Patient 2 was also still driving a car. He and his wife rated his pre-morbid knowledge of plants as 1 and cars as 2 .

\subsubsection{Control participants}

The patients were compared with ten male controls. They reflected the age (range $=50-71$ years, $M=62.7$ years, $S D=8.82$ ) and varied educational backgrounds of the patients (four had a basic school education, leaving at 15-16; three remained at school until they were 18; three received university-level education). The controls indicated their level of knowledge of cars/plants on the five-point scale above. Five controls were relatively knowledgeable about cars (i.e., ratings of 1-2), while four professed good or excellent knowledge of plants.

For tests tapping naming and word-picture matching (WPM) at the basic level, control data from age-matched healthy participants were already available and not collected from these controls. 31 participants did basic level picture naming; 27 of these also did basic-level WPM. Previous control data $(N=12)$ were also already 


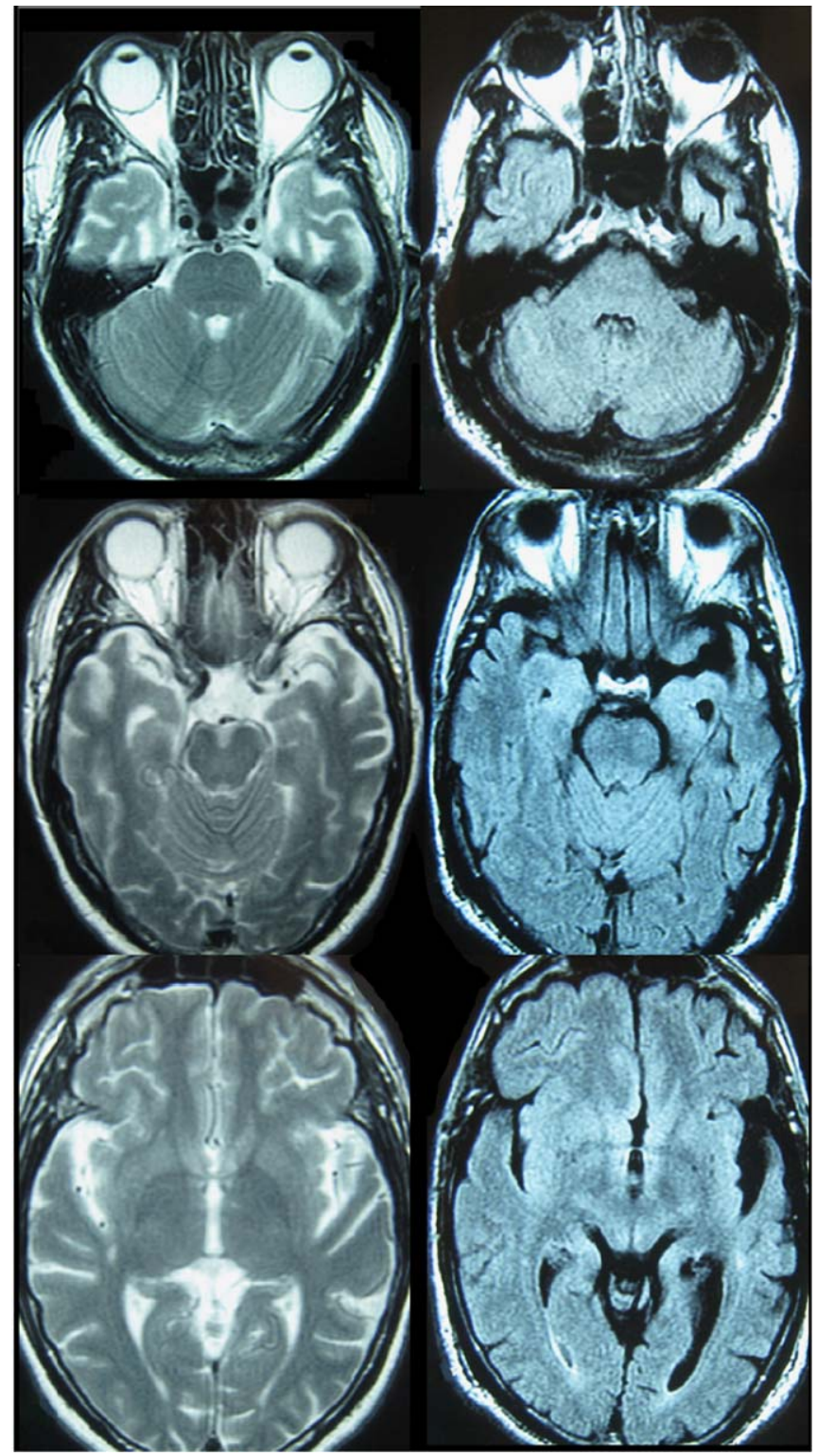

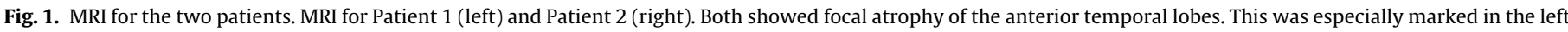
hemisphere in Patient 2 (right-hand side of image). Patient 2 also showed evidence of tissue loss in perisylvian cortex.

available for specific-level naming across a range of non-expert semantic categories (see below).

\subsection{Neuropsychological assessments}

\subsubsection{Background tests}

Background assessments are listed in Table 1. Picture naming, WPM and Camel and Cactus tests assessed knowledge of the same 64 basic-level concepts (e.g., lorry; screwdriver; cat) across different input and output modalities (Bozeat et al., 2000). The items were drawn from eight categories (domestic animals, foreign animals, birds, fruit and vegetables, large household items, small household items, tools and vehicles). (i) The patients named black and white line drawings of the objects. (ii) In the word-picture matching (WPM) test, they selected these targets from amongst nine semantically related distracters. (iii) The Camel and Cactus tests assessed judgements of semantic association (e.g., does CAMEL go with CACTUS, TREE, SUNFLOWER or ROSE) for the same items presented as words and pictures. In addition, the synonym judgement task required the patients to select the word closest in meaning to a probe word from an array of three choices (Jefferies et al., 2009). There were 96 trials.

\subsubsection{Tests of specific-level knowledge for expert and non-expert categories}

We carried out a range of assessments designed to address three theoreticallyimportant issues. The first set of tasks assessed whether premorbid expertise can produce classical category-specific dissociations in picture naming and spoken
WPM by comparing specific-level knowledge of cars and plants with other nonexpert domains. The second set of tasks evaluated the scope of expertise effects for Patient 1 by comparing the preservation of knowledge directly related to his interests/occupation with other aspects of knowledge within the general domain of "driving". The third group of tasks assessed different hypotheses about the causes of the preserved expert knowledge. For example, to test the hypothesis that expertise is completely spared in SD following cortical reorganisation of knowledge from expert domains, we compared Patients 1 and 2 with controls who were also especially knowledgeable about cars/plants. In addition, to test the hypothesis that ongoing exposure is important in the preservation of expert knowledge in Patient 1, we compared his knowledge of modern and older cars and examined his ability to relearn and retain the names of cars and other objects.

1) Category-specific preservation of expert knowledge: We compared knowledge of types and parts of cars/plants (allowing direct comparison across domains using the same style of assessment), since Patient 1's knowledge was centred on types of cars, while Patient 2 had acquired technical knowledge of the parts of plants. Patient 2 did not complete the naming assessments due to his extremely poor naming of basic-level items.

a. Modern car naming: Patient 1 and the controls attempted to name 70 coloured photographs of modern cars, presented individually.

b. WPM for modern cars: Participants selected photos of modern cars (e.g., "Which is the Ford Fiesta?") from an array of six photos showing other makes of car (e.g., Nissan, Volkswagen). There were 72 trials. 
c. WPM for types of plants: This task included plants from six sub-categories (trees, wild flowers, garden flowers, vegetables, cereals, other crops). Participants selected the targets from arrays containing plants from other sub-categories (e.g., "daisy" from amongst cereals/trees/vegetables etc.). There were six choices per trial and 64 trials.

d. Naming and WPM of parts of cars vs. other everyday objects: The participants attempted to name and select parts of cars shown on an exterior view (e.g., windscreen; indicator lights: $N=21$ ) and an interior view (e.g., steering wheel; seatbelt: $N=18$ ). The car parts were compared with components of five familiar objects (television, telephone, kettle, microwave, watch; e.g., on/off switch, television screen: $N=26$ in total). The pictures were coloured line drawings/photographs. The experimenter pointed to the parts to be named with a pencil. In WPM, participants were asked to choose one of six arrows that corresponded to a spoken word for each picture. Only the watch and kettle were used in WPM, as they had the greatest number of nameable parts $(N=15)$.

e. WPM for parts of plant: The participants were shown schematic line drawings of (1) a basic plant, with parts such as roots, leaves, flowers and seeds $(N=6)$; (2) a detailed plant, with parts such as root hairs, vascular system and petiole $(N=13)$; (3) a detailed flower, with parts such as stigma, filament and anther $(N=10)$. For all three drawings, the relevant parts were labelled with arrows. On each trial, participants were asked to choose the arrow that corresponded with the spoken target word.

f. Other specific-level entities from non-expert categories: There were two tests: (1) The Graded Faces test (Thompson, Graham, Patterson, Sahakian, \& Hodges, 2002). Thirty black-and-white photographs of famous faces varying in difficulty were presented individually for naming. Participants were probed for (a) first name, (b) surname and (c) any information about the person. As there was little difference in accuracy between first names and surnames, the analysis focuses on the production of whole names. In the WPM task, the faces were presented alongside four distracters and participants were provided with both the spoken and written name. (2) Specific-level knowledge of a range of other non-expert categories (boats, fish, birds, flowers, dogs and shoes) was assessed using an additional set of colour photographs. There were 24 items to name (e.g., "Pekinese") and 44 trials in the word-picture matching test, each with 7 choices (e.g., other dogs for Pekinese). Patient 2 did not complete these tests.

2) Scope of expertise effects: Through an extension of the assessments above, we investigated whether Patient 1's preserved knowledge of types of cars would extend to other information about cars and driving (including parts of cars, car logos, and road signs) or whether his expertise effect would be more restricted to his specific occupation and interests.

a. Spoken fluency: To supplement the naming and word-picture matching data above, knowledge of types and parts of cars and other non-expert entities was assessed in a fluency task. Participants were given one minute per category and were asked to produce as many types and parts of cars, boats and clocks as possible (total $=$ six categories).

b. Additional car tests: Patient 1 and the controls were additionally asked to name car logos $(N=30)$, non-car logos $(N=49)$ and traffic signs $(N=24)$, presented as colour pictures. Images were manipulated so that participants could not produce the correct response by reading the text.

c. Knowledge of car safety glass: Participants were given thirty factual statements about automotive glass (closely linked to Patient 1's previous employment) and decided if each statement described laminated or toughened glass (e.g., "Shatters into small pieces" $\rightarrow$ toughened glass; "Contains plastic" $\rightarrow$ laminated glass). The statements and categories were written on slips of paper and read aloud to participants. Statement sorting in this expert domain was compared with statements describing pens/pencils (e.g., "Writes with ink" $\rightarrow$ pen; "Needs to be sharpened" $\rightarrow$ pencil)

3) Hypotheses about the causes of the preserved expert knowledge: Additional assessments were devised to investigate whether Patient 1's ongoing exposure to cars helped to preserve his expert knowledge.

a. Naming and WPM for older cars: These assessments examined knowledge of older cars from the 1980s, which would have been highly familiar 25 years ago but are now rarely seen on the road. The picture naming and WPM tasks included 56 and 54 items respectively. These tests were compared with naming and WPM for modern cars. As for those tests described previously, stimuli were coloured photographs and participants in the WPM task were asked to find a particular car (e.g., "Ford Fiesta") from an array of six photos showing different makes of car (e.g., Nissan, Volkswagen).

b. Relearning of car and non-car names: Patient 1 was given training to assess his ability to learn and retain the names of three sets of twenty items that he had been unable to name on two previous occasions. Set 1 contained unusual or older cars that he did not recognise. Set 2 was composed of non-car items that he provided some correct information about (e.g., axe $\rightarrow$ "how you break things, bang it down"; suitcase $\rightarrow$ "bag when you're going abroad"). Set 3 contained non-car items that he knew very little about (e.g., "lobster" $\rightarrow$ "no idea"; bell $\rightarrow$ "what is that?"). Sets 2 and 3 were matched for word frequency using the Celex database (average frequency $=11.1$ and 12.3 respectively). During training, he was shown these items as pictures in a random order. He attempted to name each item, checked his response by lifting a flap of paper concealing the target name and then repeated the correct name aloud three times after it was read to him. He was asked to practice the items once a day (either with the experimenter or his wife): in reality, he practised them six times over the course of ten days. Patient 1's retention of the names was then assessed after three, six and nine weeks.

\subsection{Statistical tests}

When the WPM tests had variable numbers of choices, the raw data was corrected for guessing using the following equation: $S=R-(W /(k-1))$. In this equation, taken from Diamond and Evans (1973), $S$ represents the corrected score, $R$ is the number of correct items, $W$ is the number of incorrect items and $k$ is the number of response options. Nevertheless, analysis of uncorrected WPM yielded the same pattern of results.

We used Crawford \& Garthwaite (2002) 'singlims' procedure to establish whether patients were significantly impaired relative to controls on each test: this method uses a modified $t$-statistic to examine whether an individual is significantly impaired, relative to normal performance, taking into account the sample size and degree of variability in the control group. Potential dissociations between assessments were examined using the Revised Standardised Difference Test (RSDT) (Crawford \& Garthwaite, 2005), which uses modified $t$-tests to establish whether the difference between a patient's scores on two tasks varies significantly from the differences observed in a control sample. Performance on the two conditions is expressed as a standardised score, and the degree of difference between these conditions is then examined, taking into account the sample size and degree of variability in the control group, and the correlation between the two measures being compared. All $p$ values are one-tailed unless otherwise stated.

\section{Results}

\subsection{Classical dissociation for car knowledge vs. other domains}

Patient 1 (car expert) showed a pronounced general semantic impairment but marked preservation of car knowledge. His naming of types of modern car was within normal limits (there was no significant difference from age and gender matched controls, $t(9)<1)$. In contrast, he was highly impaired at naming non-car objects at the basic level $(t(30)=-30.3, p<.001)$ and he performed at floor on naming tests that probed faces and other specificlevel stimuli $(t(9)=-4.3, p=.002)$. Patient 1 's naming advantage for modern cars over other specific items was highly significant (cars vs. faces, $\chi^{2}(1)=25.2, p<.0001$; cars vs. other specific-level items, $\left.\chi^{2}(1)=20.9, p<.0001\right)$. Strikingly, his naming of modern cars at the specific level was better than his basic-level object naming $\chi^{2}(1)=15.1, p<.0001$ (see Fig. 2 ). In contrast, controls showed significantly better naming of basic-level concepts than types of car (Mann-Whitney $U=1, p<.0001$ ).

Further classical dissociations between car and non-car knowledge for Patient 1 were seen in word-picture matching (WPM; see Fig. 3). WPM for modern car makes was within normal limits $(t(9)<1)$. In contrast, performance was severely impaired for faces $(t(9)=-4.6, p=.001)$, plants $(t(9)=-16.9, p<.001)$, and other stimuli at the specific level $(t(9)=-17.5, p<.001)$ and basic level $(t(26)=-78.1, p<.001)$. Patient 1 showed superior performance for modern cars at the specific level compared with non-car objects at

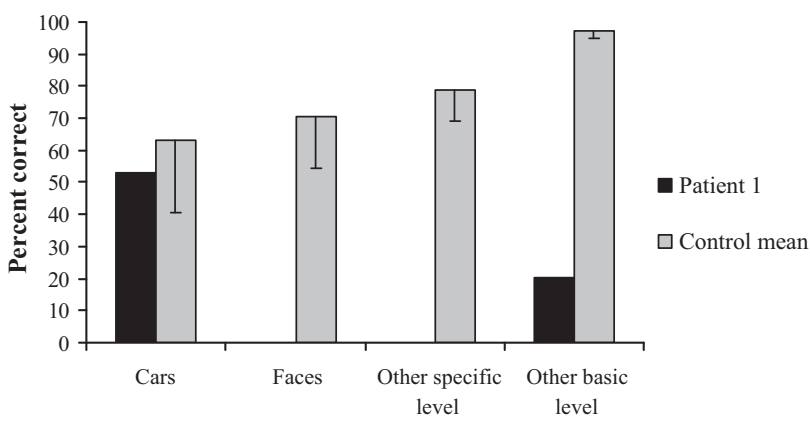

Fig. 2. Naming of cars vs. other categories for Patient 1 (car expert). Error bars show 1 standard deviation around the control mean. Patient 1 was at floor on faces and other specific-level items. 


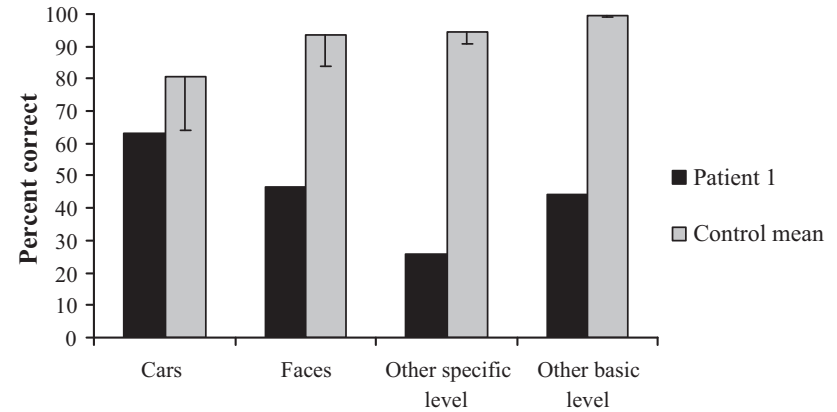

Fig. 3. Word-picture matching for cars vs. other categories for Patient 1 (car expert). Error bars show 1 standard deviation around the control mean. Correction for guessing was applied to these data (see Section 2.3).

the basic level $\left(\chi^{2}(1)=4.8, p=.03\right)$, an extremely unusual pattern for SD where knowledge of more specific categories is typically more vulnerable (Rogers et al., 2004). Specific-level WPM was also significantly better for modern cars than for a range of other objects (including plants: $\chi^{2}(1)=59.0, p<.001$, and items taken from a range of different categories: $\chi^{2}(1)=15.0, p<.001$; comparison with face WPM was not significant). The RSDT test confirmed that the difference between WPM for modern makes of car and non-car stimuli was significantly greater in Patient 1 than controls in every potential comparison (cars vs. faces: $t(9)=2.6, p<.03$; cars vs. plants: $t(9)=10.0, p<.001$; cars vs. specific items from different categories: $t(9)=9.9, p<.001)$. In summary, Patient 1 showed a classical dissociation between cars and other objects in both naming and WPM. Moreover, since he showed a reversal of the basic-level advantage in both tasks, this category-specific pattern cannot be explained in terms of overall difficulty of the tasks.

\subsection{Double dissociation between cars and plants}

To confirm that car knowledge is not selectively spared in the context of semantic degeneration regardless of expertise, we compared Patient 1 (car expert) with a second patient (plant expert). We focused on WPM because Patient 2 had verbal production difficulties in addition to semantic impairment and thus demonstrated floor effects in confrontational naming (see Section 2.1.1 above). Given that Patient 2 was a biologist with technical expertise, we supplemented the tests above (examining types of plants/cars) with WPM for terms describing parts of plants and cars. The two patients showed a double dissociation for knowledge of modern cars and plants: Patient 1 was better than Patient 2 on the car tests (types of car: $\chi^{2}(1)=18.78, p<.0001$; parts of car: $\left.\chi^{2}(1)=11.40, p=.001\right)$, whereas Patient 2 was better than Patient 1 on the plant tests (types of plants: $\chi^{2}(1)=32.6, p<.0001$; parts of plants: $\chi^{2}(1)=14.6, p<.0001$; see Figs. 4 and 5). Patient 1 showed a classical dissociation between types of cars vs. plants (i.e., knowledge of makes of modern car did not differ significantly from controls, while performance for types of plants was profoundly impaired; see above). He also showed a strong dissociation between knowledge of parts of cars/plants, with mild impairment for parts of cars $(t(9)=-3.3, p=.010)$ and a more pronounced deficit for parts of plants $(t(9)=-14.8, p<.001)$. The difference between these two domains significantly exceeded that seen in the control sample (RSDT test: $t(9)=6.5, p<.001$ ). Patient 2 showed the reverse dissociation - his WPM for parts of plants was within normal limits $(t(9)<1)$, while parts of cars were significantly impaired $(t(9)=-93.4, p<.001)$. This discrepancy was again larger than expected from the control sample $(t(9)=34.3, p<.001)$ and constitutes a classical dissociation. However, Patient 2 was

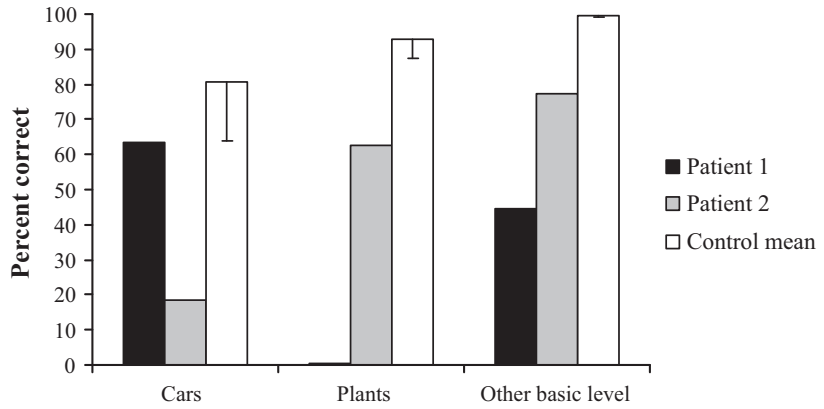

Fig. 4. Word-picture matching for types of cars, plants and other basic-level items. Error bars show 1 standard deviation around the control mean. Correction for guessing was applied to these data (see Section 2.3).

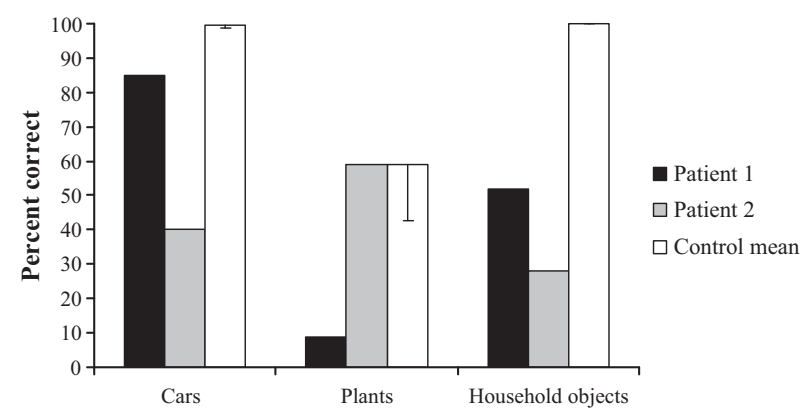

Fig. 5. Word-picture matching for parts of cars, plants and household objects. Error bars show 1 standard deviation around the control mean. Correction for guessing was applied to these data (see Section 2.3).

impaired on WPM for types of cars/plants in both domains (plants: $t(9)=-5.5, p<.001$; modern cars: $t(9)=-3.6, p<.001)$.

\subsection{Influence of expertise within a domain-general semantic} store

The findings above confirm that a classical double dissociation can arise from premorbid expertise in patients with progressive semantic degradation. The mechanisms underlying this effect, however, remain unclear. One possibility is that expertise forces a category-specific reorganisation of cortical function, whereby discrete regions of cortex become dedicated to the expert domain. For example, expertise is known to increase the involvement of the fusiform face area (FFA) in the recognition of specific entities, such as types of car (Bukach, Gauthier, \& Tarr, 2006; Gauthier et al., 2000). The FFA was relatively spared in Patients 1 and 2 (and in SD more widely): this might give rise to the preservation of expert knowledge. An alternative possibility is that concepts within expert domains are more strongly differentiated within the domain-general ATL semantic system so that, when this system degrades, semantic acuity is reduced for both expert and nonexpert concepts (Rogers \& McClelland, 2004). On this view expert concepts may appear to be preserved when compared with a random sample of age- and gender-matched controls, but are in fact degraded relative to the individual's prior state of knowledge. Comparison of Patient 1 with five healthy car experts-controls who rated their knowledge of cars as good or excellent-indicated that his performance was, in fact, impaired relative to this group (naming modern makes of car: $t(4)=-2.6, p=.03$; WPM for modern makes of car: $t(4)=-4.6, p=.01$; see Fig. 6 ). Patient 2 was not impaired in his knowledge of parts of plants even when compared to four healthy participants with good or excellent knowledge of plants, but his knowledge of types of plants was more seriously compromised (see above). 


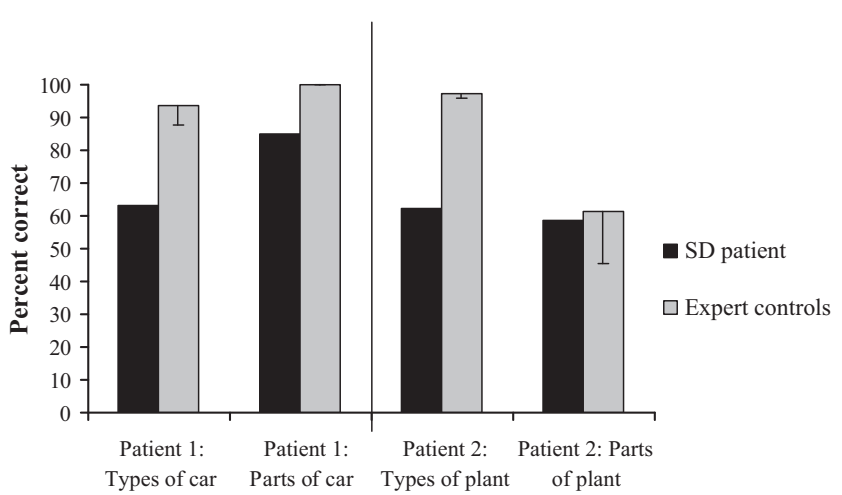

Fig. 6. Word-picture matching for patients compared with expert controls. Error bars show 1 standard deviation around the control mean. Correction for guessing was applied to these data (see Section 2.3).

\subsection{Narrowness of expertise effects: additional tests of car knowledge}

The findings above suggest that expertise effects in progressive semantic degeneration are relatively restricted in scope: Patient 1 , with expert knowledge of different types of car, nevertheless showed substantial loss of knowledge about the component parts of cars in the WPM tests above. Similarly, Patient 2, with technical expertise in plant biology, showed preserved knowledge of the parts of plants and flowers but significant impairment in WPM tests tapping his knowledge of types of plants. This demonstrates that expertise does not necessarily protect related spheres of knowledge from degradation.

We designed some additional assessments to specifically target this issue in Patient 1. (i) We used naming and fluency tasks to directly compare Patient 1's knowledge of types and parts of cars, supplementing our WPM results. The data, shown in Fig. 7 , confirms the pattern described above. Patient 1 was able to name modern makes of car at a normal level (see above) but was substantially impaired at naming the interior and exterior parts of a $\operatorname{car}(t(9)=18.3, p<.0001)$. This difference in performance greatly exceeded that seen in healthy controls (RSDT: $t(9)=10.6, p<.0001$ ). Similarly, in the fluency assessments, shown in Fig. 8, Patient 1 was able to generate a normal number of car types $(t(5)<1$; due to experimenter error, data were only available for six of the controls). In contrast, he showed substantial impairment across all other conditions, tapping generation of types of boat/clock and parts of cars/boats/clocks $(t(9)>3.4, p<.004)$. The difference in fluency for types vs. parts of cars again exceeded that seen in controls (RSDT: $t(5)=2.04$, one-tailed $p=.05$ ).

(ii) We examined Patient 1's knowledge of car logos, non-car logos and road signs (data shown in Fig. 9). He was unimpaired at naming car logos when compared with the full set of controls $(t(8)=1.4$, n.s.; one control participant was not tested due

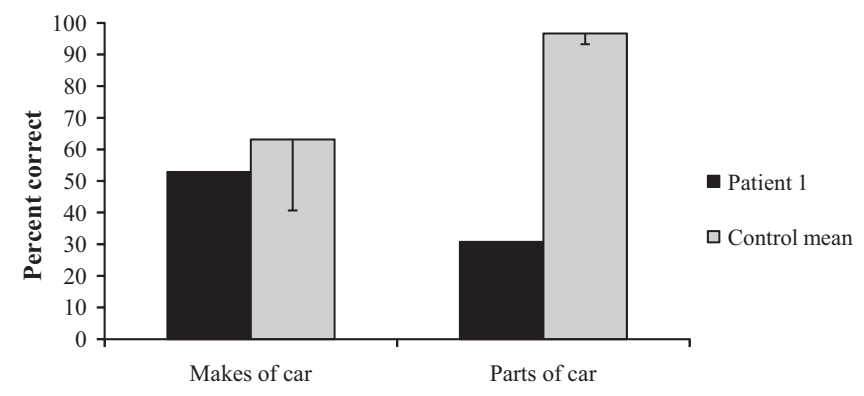

Fig. 7. Naming of makes of modern car and car parts. Error bars show 1 standard deviation around the control mean.

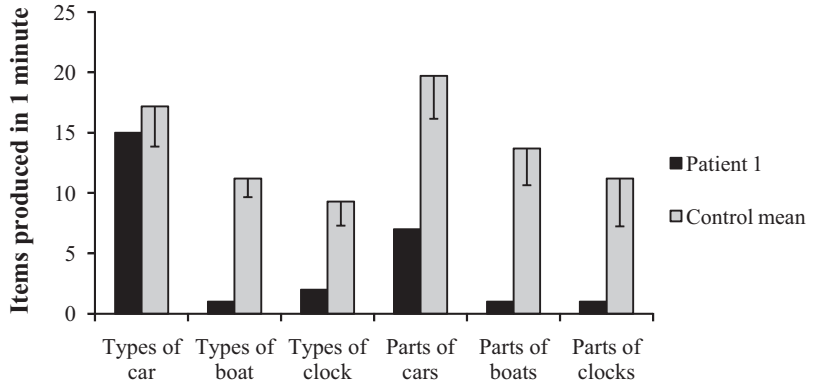

Fig. 8. Fluency for types and parts of cars, boats and clocks. Error bars show 1 standard deviation around the control mean.

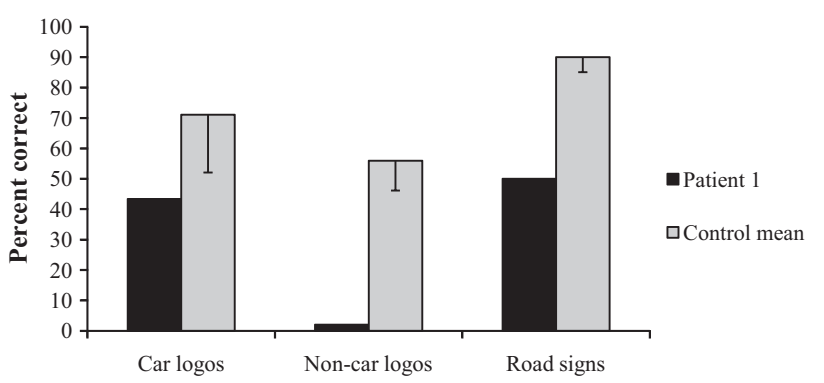

Fig. 9. Naming of car logos, non-car logos and road signs. Error bars show 1 standard deviation around the control mean.

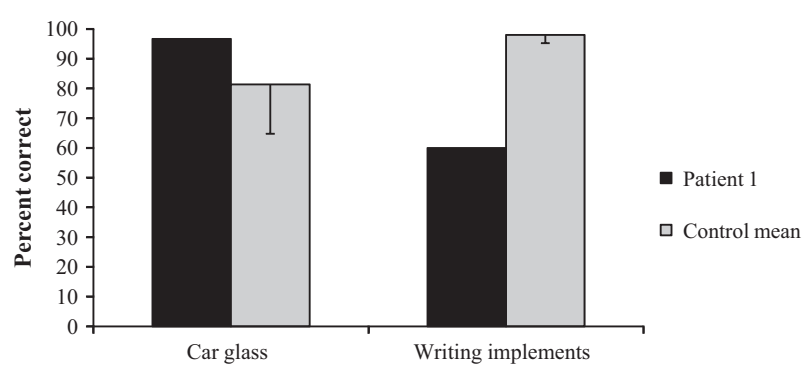

Fig. 10. Statement sorting for car glass and writing implements. Error bars show 1 standard deviation around the control mean.

to time constraints). In contrast, he was substantially impaired at naming non-car logos $(t(9)=5.3, p=.0003)$ and road signs $(t(9)=7.8, p<.0001)$. Patient 1 's expertise effects were again relatively restricted in scope: he showed a much bigger difference between car logos and road signs than the control participants $(i(8)=3.5, p=.0008)$, even though both sets of stimuli were coloured line drawings related to cars/driving.

(iii) Finally, we investigated Patient 1's knowledge of automotive glass, to establish if his long period of employment in this industry would produce expertise effects even in the face of global semantic degradation. Patient 1 was able to sort statements about car safety glass almost flawlessly and he was unimpaired on this task $(t(9)<1)$. In contrast, his sorting of pencil/pen statements was much more prone to error (see Fig. $10 ; \chi^{2}(1)=11.9$, exact one-tailed $p=.001$ ) and was substantially impaired relative to control performance $(t(9)=12.9, p<.0001)$. Moreover, Patient 1 showed a larger difference between these two test versions than the controls (RSDT: $t(9)=37.7, p<.0001)$.

\subsection{Ongoing exposure and expertise effects: modern vs. older cars}

The findings above suggest that, to a degree, expert knowledge can be protected from global semantic degradation, resulting in better performance for specific-level expert items than basic-level 


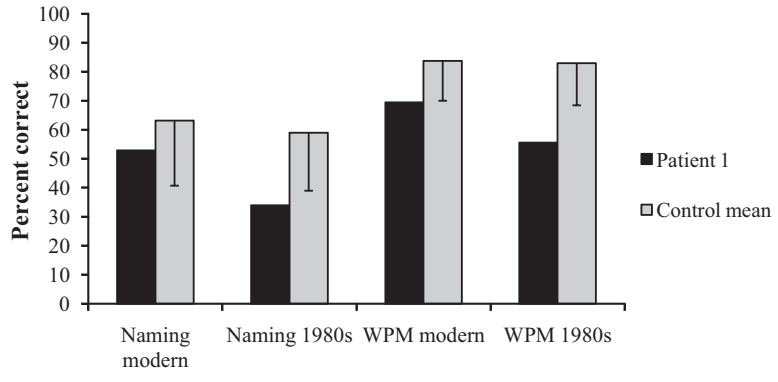

Fig. 11. Naming and word-picture matching for modern and 1980s cars. Error bars show 1 standard deviation around the control mean. WPM = word-picture matching with six choices.

non-expert ones. As noted in the Introduction, limited previous research on this topic has not always observed this pattern. This raises the question of whether there are factors that benefit the retention of expert knowledge in particular SD cases: for example, some patients may retain a keen interest in their expert domain and, as a result, continue to encounter expert concepts more frequently than other matched concepts as their semantic knowledge degrades. We used the contrast between modern cars and older cars from the 1980s in Patient 1 to address the possible role of continuing exposure (see Fig. 11). Patient 1 was not significantly impaired at naming pictures of either modern or 1980s cars when compared with the full sample of controls $(t(9)<1.2$, n.s. ). However, RSDT analysis indicated that Patient 1 showed a greater difference between modern and older cars than the controls - in other words, his naming of 1980 s cars was poorer than would be expected given his ability to name modern makes of $\operatorname{car}(t(9)=2.0, p=.04)$. He was also severely impaired at naming 1980 s cars when compared with five healthy car experts $(t(4)=-2.9, p=.009)$.

A similar pattern emerged in the WPM results: Patient 1 was not impaired at recognising modern cars when compared with the full sample of controls $(t(9)<1, n . s$. ) but he was marginally impaired at WPM for 1980 s cars $(t(9)=-1.8, p=.05)$. RSDT analysis was again used to compare the comprehension of modern and older cars: Patient 1 showed a numerically larger difference between these two test versions than the controls, which approached significance $(t(9)=1.4, p<.1)$. Finally, Patient 1 was substantially impaired at WPM for 1980s cars when compared with the five healthy car experts $(t(4)=-4.1, p=.007)$.

\subsection{Relearning of car and non-car names}

Fig. 12 shows Patient 1's naming of (1) previously unnamed cars, (2) objects that he recognised but could not name and (3) totally unknown items. The graph shows the number of items successfully named after each practice session and at three follow-up intervals.

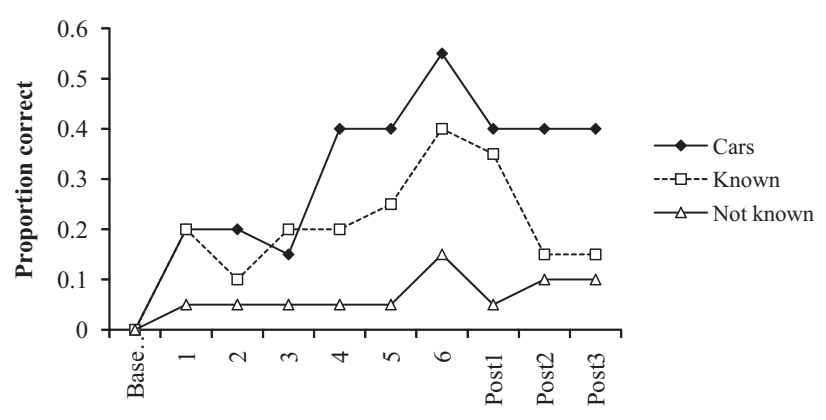

Fig. 12. Effect of relearning for cars, known objects and semantically degraded items. Base $=$ baseline naming performance $(0$ items named prior to training). $1-6=$ training sessions. Post $1-3=$ post-learning naming performance.
Overall, Patient 1 showed a highly significant effect of practice (session 1 vs. session 6 of practice; McNemar Exact 1-sided $p=.0005$ ). There was also a significant degree of forgetting over the followup period (final session of practise vs. follow-up 3; McNemar Exact 1 -sided $p=.006$ ). The learning effect was significant or approached significance for both cars and recognised objects (McNemar Exact 1 -sided $p=.02$ and $p=.06$ respectively). However, Patient 1 showed no ability to learn the names of totally unknown objects (McNemar Exact 1-sided $p=.3$ ). In addition, the names of the cars were retained over a nine-week period (there was no significant forgetting between the final session of practice and the last follow-up; McNemar Exact 1-sided $p=.13$ ), whereas the degree of forgetting for partially-known non-car items approached significance (McNemar Exact 1-sided $p=.06$ ). Two further sets of control items which were not practised (unnamed cars and recognised objects) did not change in accuracy over the course of the relearning study.

\section{Discussion}

This study provides a striking demonstration that individual differences in pre-morbid experience can produce apparent category-specific double-dissociations. We had an unusual opportunity to study two individuals with known areas of pre-morbid expertise, both suffering from progressive semantic degradation and atrophy within ATL regions linked to the representation of amodal and category-general conceptual knowledge (as opposed to specific sensory and motor features). Individual differences in the patients' knowledge of cars and plants interacted with their domain-general dissolution of conceptual knowledge to produce islands of preserved understanding. Both patients were within the normal range on some tests tapping their expert semantic domain, despite severe impairment across a range of standard semantic tests in other domains. Moreover, when the two patients were directly compared on tests assessing knowledge of cars and plants, they showed a classical double dissociation. However, both patients also showed clear evidence of impairment in their expert domain when compared with healthy controls who also professed a degree of expertise for cars/plants. This indicates that expertise does not force a category-specific reorganisation of cortical function; instead, expertise effects emerge in the context of domain-general semantic dissolution.

Parallel distributed processing (PDP) models of semantic cognition suggest that expertise in a particular domain may increase the differentiation of specific-level concepts. Rogers and McClelland (2004) examined such effects in a simple computer model of semantic memory (Rumelhart \& Todd, 1993) by presenting types of either fish or birds (e.g., cod, sparrow) more frequently than other items during training. The model captured a variety of expertise effects seen in healthy subjects - for example, the finding that experts prefer to name items at the specific as opposed to the basic level (e.g., "cod" rather than "fish") and are equally fast at making category decisions at these two levels (Johnson \& Mervis, 1997; Tanaka \& Taylor, 1991). This increased differentiation of expert concepts within the semantic system has clear consequences for the fate of expert and non-expert knowledge in SD, as the breakdown of semantic knowledge in this condition is strongly influenced by the extent to which concepts are differentiated premorbidly. At a mild stage of the disease, SD patients lose the ability to make fine distinctions between highly similar specific-level concepts (e.g., cod vs. salmon), because the attractors that represent these concepts are highly similar and liable to collapse together (Rogers et al., 2004). More general semantic distinctions (e.g., fish vs. bird) are relatively robust in the face of SD because their attractor states are more distinct. On this view, expert concepts should be relatively preserved in the face of global semantic degradation because they are more 
Table 2

Summary of SD case reports with known areas of premorbid expertise.

\begin{tabular}{|c|c|c|c|c|}
\hline Expertise & Study & Knowledge retained? & $\mathrm{AOA}$ & Ongoing exposure? \\
\hline Artist & Robinson \& Cipolotti, 2001 & $\sqrt{ }$ & Early? & Yes \\
\hline Car enthusiast & Current study & $\sqrt{ }$ ? Impaired relative to expert controls & Early & Yes \\
\hline Trumpter & Omar et al., 2010 & $\sqrt{ }$ ? Preserved musical notation and note names; poor naming of famous tunes & Early? & Yes \\
\hline Botanist & Current study & $\sqrt{ }$ ? Good knowledge of parts of plants (though poor naming) & Early & Yes? \\
\hline Surgeon & Graham et al. (1999a,b) & $\times$ & Late & No \\
\hline Bowls player & Graham et al. (1997) & $\times$ Poor knowledge of bowls vocabulary & Late & Yes \\
\hline Golfer & Graham et al. (1997) & $\times$ Poor knowledge of golf vocabulary & Late & Yes \\
\hline
\end{tabular}

$\mathrm{AOA}=$ age-of-acquisition, early = known childhood interest in domain of expertise. 'Early?' denotes that early expertise is likely although unconfirmed in the case reports.

differentiated. For a car expert, highly similar specific-level concepts such as Porsche and Ferrari are represented by more distinct patterns of activation than for a non-expert: although these attractor states will start to collapse together in a patient with SD, these concepts might still be differentiated to the same degree as in a healthy non-expert.

By this account, expertise-related category-specific impairment follows greater premorbid differentiation of knowledge in the expert domain, and this should be observable before the onset of disease. However, premorbid differences in semantic tests would not be predicted in all category-specific cases (i.e., patients who show category effects following damage to sensory or motor features would not necessarily show category differences premorbidly). Unfortunately, for many patients in neuropsychological studies, little or nothing is known about the relative strength of premorbid knowledge across different categories, and this makes it potentially difficult to differentiate between (i) damage to category-specific semantic representations and (ii) category effects that arise from premorbid knowledge combined with general (category-neutral) semantic degeneration (as in this study). However, expertise effects are perhaps more likely to account for dissociations between relatively narrow categories, as opposed to broader distinctions between living and non-living things.

Rogers and McClelland (2004) noted that expertise effects can be particularly narrow because experts focus on different types of knowledge even within the same domain: the experiences of a classic car enthusiast might be weighted towards visual features that are important for distinguishing between visually-similar cars, while a car mechanic will have greater knowledge of the shared internal components of cars. These different experiences might give rise to different kinds of expertise: for example, biologists and park keepers use different categories when sorting the same set of trees (Medin et al., 1997), indicating that expertise effects can be highly specific. Likewise, the expertise effects observed in our study were relatively restricted in scope: Patient 1 showed preserved knowledge of types of cars (but not of their component parts), while Patient 2 showed excellent understanding of the parts of plants in line with his technical expertise (but impaired knowledge of types of plants). Rogers and McClelland (2004) were able to produce PDP models with different types of expertise within the same domain by providing more frequent training on either is properties (i.e., canary is yellow; important for knowledge of visual features) or can properties (i.e., canary can sing; important for knowledge of an item's behaviour). Similarly, differential exposure to visual features and knowledge of component parts (e.g., has properties, also included in the PDP model) might be able to account for the specific nature of the expertise effects in Patients 1 and 2.

The models of Rogers and McClelland (2004) therefore provide a useful framework for understanding how the preservation of expert knowledge in SD patients might emerge from premorbid differences in the frequency with which information from different domains is encountered or trained. However, other factors might also be important in determining the strength of expertise effects in
$\mathrm{SD}$, as the limited literature on this topic suggests that there is substantial variation between individuals (see Section 1 and Table 2). (1) Some SD patients retain an interest in their domain of expertise, making it likely that they will continue to encounter expert concepts more frequently than other concepts during the course of the disease: this could substantially strengthen the size of the expertise effects in these individuals. (2) In addition, some people develop expertise through a keen interest in a particular topic from an early age, while others acquire technical expertise as an adult. Given that patients with SD show better retention of words and concepts that are learned at an early age (Lambon Ralph, Graham, Ellis, \& Hodges, 1998; Woollams et al., 2008), age of acquisition might also be a crucial factor in determining the survival of expert knowledge.

In order to explore the importance of the first factor, we conducted several experiments that explicitly examined the role of continued exposure in the preservation of expert knowledge in Patient 1 . We found that Patient 1 was more impaired at 1980 s cars compared with those still on the road; in addition, he showed a larger difference in his naming of older and modern cars than the control group, suggesting that ongoing exposure played an important role in the survival of his expert car knowledge. These findings are consistent with the proposal that the recent experiences of patients with SD can influence their performance on semantic tasks (e.g., Snowden, Griffiths, \& Neary, 1995; Snowden, Griffiths, \& Neary, 1996), reflecting the fact that their memory for recent events is relatively preserved. Snowden et al., (1994) have shown that patients with SD sometimes produce low frequency vocabulary in natural conversation, despite severe impairment of picture naming: this seems to follow from the fact that their conversation revolves around recent events. Patients also show better comprehension of (i) personally relevant (and therefore still frequently-encountered) names/places, compared with nonrelevant ones and (ii) recently-learned compared with older items, regardless of whether this information is semantic (e.g., monetary system; famous people) or autobiographical (recent vs. distant events; Snowden et al., 1996).

Our relearning study also supports the view that ongoing experience can assist the survival of expert knowledge. Patient 1 could readily learn the names of previously unnamed cars and retain this knowledge over a few months. His ability to learn non-car names was also influenced by his residual knowledge of these items but, interestingly, he showed rapid forgetting of non-car names when he stopped rehearsing them. These findings suggest two effects might be at play: (i) concept names in SD can be partially protected from loss by ongoing rehearsal and (ii) the effects of this continued learning are relatively enduring for concepts drawn from an expert domain containing many related concepts, but fragile for 'isolated' concepts that cannot benefit to the same degree from shared structure with 'known' semantic neighbours. Therefore, Patient 1's ongoing interest in cars (which presumably increased the frequency with which he encountered these concepts) appears to have had a substantial and enduring impact on his semantic performance in this domain. Several previous studies have simi- 
larly shown better relearning of object names in SD for items with residual knowledge (Jokel, Rochon, \& Leonard, 2006; Snowden \& Neary, 2002), suggesting that new learning interacts with existing knowledge in the ATL, even in SD patients with pronounced semantic degradation. These findings would follow naturally from views about how the hippocampal complex and neocortex operate together. McClelland, McNaughton, \& O' Reilly (1995) have proposed that incoming sensory stimuli activate cortical representations and links are formed between these representations in the hippocampus. The hippocampal trace or index therefore depends upon the presence of appropriate semantic representations in the cortex. This explains why new learning is sensitive to the degree of residual knowledge in SD and also how neocortical knowledge might be refreshed by new learning even as semantic representations are degrading (see Lambon Ralph, Sage, Jones, \& Mayberry, 2010; Mayberry, Sage, Ehsan, \& Lambon Ralph, submitted for publication, for further discussion).

The variation between patients shown in Table 2 also suggests a possible role for age of acquisition in the survival of expert knowledge in SD: it seems that some patients fail to retain their expert knowledge despite ongoing exposure. In particular, Graham and colleagues (Graham et al., 1997; Graham, Lambon Ralph, \& Hodges, 1999a) found that two SD patients, a keen golfer and a bowls player, failed to understand or produce golf/bowls sporting terms in conversation, despite continuing to play. They did, however, retain excellent procedural knowledge. What might account for this variability across studies? Table 2 reveals that 4/7 SD patients with known premorbid expertise showed at least partial preservation of their expert knowledge - and in all of these cases, an early interest in the topic was either confirmed or is likely (reflecting the fact that artists and musicians spend many years acquiring their skills). In contrast, the three patients who did not retain their expertise had, in every case, acquired their knowledge (of golf, bowls and surgery) as an adult.

In conclusion, the current findings have important consequences for our understanding of the neural basis of conceptual knowledge and for neuropsychology/cognitive science more broadly. It is widely assumed that case studies exemplifying classical or strong double-dissociations between two processes are evidence for functionally independent cognitive systems. While this conclusion is valid in some instances, our findings show that, contrary to the standard assumptions of cognitive neuropsychology, classical dissociations can also emerge as a result of individual differences in pre-morbid experience.

\section{Acknowledgements}

We are indebted to the patients and their carers for their generous assistance with this study. We would like to thank Mark Doran and colleagues at the Walton Centre for Neurology and Neurosurgery, Liverpool, UK for referring the patients to us. We also acknowledge the assistance of Katie Noble (test construction), Victoria Scott, Hayley Fairclough and Rebecca Robinson (testing of control participants) and Sheeba Ehsan (follow-up assessment of patients). The work was supported by a grant from the NIMH (MH64445), an RCUK fellowship awarded to E. Jefferies and an MRC programme grant (G0501632).

\section{References}

Albanese, E., Capitani, E., Barbarotto, R., \& Laiacona, M. (2000). Semantic category dissociations, familiarity and gender. Cortex, 36(5), 733-746.

Barbarotto, R., Laiacona, M., Macchi, V., \& Capitani, E. (2002). Picture reality decision, semantic categories and gender: A new set of pictures with norms and an experimental study. Neuropsychologia, 40, 1637-1653.

Barsalou, L. W. (1999). Perceptual symbol systems. Behavioural and Brain Sciences, 22, 577-660.
Bird, H., Lambon Ralph, M. A., Patterson, K., \& Hodges, J. R. (2000). The rise and fall of frequency and imageability: Noun and verb production in semantic dementia. Brain and Language, 73(17-49).

Bozeat, S., Lambon Ralph, M. A., Patterson, K., Garrard, P., \& Hodges, J. R. (2000). Nonverbal semantic impairment in semantic dementia. Neuropsychologia, 38(9), 1207-1215.

Bukach, C. M., Gauthier, I., \& Tarr, M. J. (2006). Beyond faces and modularity: The power of an expertise framework. Trends in Cognitive Sciences, 10, 159-166.

Butterworth, B., Cappelletti, M., \& Kopelman, M. (2001). Category specificity in reading and writing: The case of number words. Nature Neuroscience, 4(8), 784-786.

Capitani, E., Laiacona, M., Mahon, B., \& Caramazza, A. (2003). What are the facts of semantic category-specific deficits? A critical review of the clinical evidence. Cognitive Neuropsychology, 20, 213-261.

Caramazza, A., \& Shelton, J. R. (1998). Domain-specific knowledge systems in the brain: The animate-inanimate distinction. Journal of Cognitive Neuroscience, 10 , $1-34$.

Chao, L. L., Haxby, J. V., \& Martin, A. (1999). Attribute-based neural substrates in temporal cortex for perceiving and knowing about objects. Nature Neuroscience. 2(10), 913-919.

Coccia, M., Bartolini, M., Luzzi, S., Provinciali, L., \& Lambon Ralph, M. A. (2004) Semantic memory is an amodal, dynamic system: Evidence from the interaction of naming and object use in semantic dementia. Cognitive Neuropsychology, 21(5), 513-527.

Coltheart, M.(2004). Are there lexicons? Quarterly Journal of Experimental Psychology, 57A, 1153-1171.

Crawford, J. R., \& Garthwaite, P. H. (2002). Investigation of the single case in neuropsychology: Confidence limits on the abnormality of test scores and test score differences. Neuropsychologia, 40, 1196-1208.

Crawford,J. R., \& Garthwaite, P.H.(2005). Testing for suspected impairments and dissociations in single-case studies in neuropsychology: Evaluation of alternatives using Monte Carlo simulations and revised tests for dissociations. Neuropsychology, 19, 318-331.

Damasio, H., Grabowski, T. J., Tranel, D., Hichwa, R. D., \& Damasio, A. R. (1996). A neural basis for lexical retrieval. Nature, 380, 499-505.

Damasio, H., Tranel, D., Grabowski, T., Adolphs, R., \& Damasio, A. (2004). Neural systems behind word and concept retrieval. Cognition, 92(1-2), 179-229.

Diamond, J., \& Evans, W. (1973). The correction for guessing. Review of Educational Research, 43(2), 181-191.

Farah, M. J., \& McClelland, J. L. (1991). A computational model of semantic memory impairment: Modality specificity and emergent category specificity. Journal of Experimental Psychology: General, 120, 339-357.

Funnell, E., \& De Mornay Davies, P.(1996). JBR: A reassessment of concept familiarity and a category-specific disorder for living things. Neurocase, 2(6), 461-474.

Gainotti, G., Silveri, M. C., Daniele, A., \& Giustolisi, L. (1995). Neuroanatomical correlates of category-specific semantic disorders: A critical survey. Memory, 3(3-4), 247-\&.

Galton, C. J., Patterson, K., Graham, K., Lambon-Ralph, M. A., Williams, G., Antoun, N., et al. (2001). Differing patterns of temporal atrophy in Alzheimer's disease and semantic dementia. Neurology, 57(2), 216-225.

Gauthier, I., Skudlarski, P., Gore, J. C., \& Anderson, A. W. (2000). Expertise for cars and birds recruits brain areas involved in face recognition. Nature Neuroscience, 3, 191-197.

Graham, K. S., Lambon Ralph, M. A., \& Hodges, J. R. (1997). Determining the impact of autobiographical experience on meaning: New insights from investigating sports-related vocabulary and knowledge in two cases with semantic dementia. Cognitive Neuropsychology, 14(6), 801-837.

Graham, K. S., Lambon Ralph, M. A., \& Hodges, J. R. (1999). A questionable semantics: The interaction between semantic knowledge and autobiographical experience in semantic dementia. Cognitive Neuropsychology, 16(7), 689-698.

Graham, K. S., Patterson, K., Pratt, K. H., \& Hodges, J. R. (1999). Relearning and subsequent forgetting of semantic category exemplars in a case of semantic dementia. Neuropsychology, 13(3), 359-380.

Hodges, J. R., Graham, N., \& Patterson, K. (1995). Charting the progression in semantic dementia: Implications for the organisation of semantic memory. Memory, 3(3-4), 463-495.

Hodges, J. R., Patterson, K., Oxbury, S., \& Funnell, E. (1992). Semantic dementia: Progressive fluent aphasia with temporal lobe atrophy. Brain, 115(6), 1783-1806.

Humphreys, G. W., \& Forde, E. M. E. (2001). Hierarchies, similarity and interactivity in object recognition: Category-specific neuropsychological deficits. Behavioral and Brain Sciences, 24, 453-509.

Jefferies, E., Bateman, D., \& Lambon Ralph, M. A. (2005). The role of the tempora lobe semantic system in number knowledge: Evidence from late-stage semantic dementia. Neuropsychologia, 43(6), 887-905.

Jefferies, E., Patterson, K., Jones, R. W., \& Lambon Ralph, M. A. (2009). Comprehension of concrete and abstract words in semantic dementia. Neuropsychology, 23, 492-499.

Johnson, K. E., \& Mervis, C. B. (1997). Effects of varying levels of expertise on the basic level of categorisation. Journal of Experimental Psychology: General, 126 248-277.

Jokel, R., Rochon, E., \& Leonard, C. (2006). Treating anomia in semantic dementia: Improvement, maintenance, or both? Neuropsychological Rehabilitation, 16, 241-256.

Lambon Ralph, M. A., Graham, K. S., Ellis, A. W., \& Hodges, J. R. (1998). Naming in semantic dementia - What matters? Neuropsychologia, 36(8), 775-784. 
Lambon Ralph, M. A., Lowe, C., \& Rogers, T. T. (2007). Neural basis of category-specific semantic deficits for living things: Evidence from semantic dementia, HSVE and a neural network model. Brain, 130, 1127-1137.

Lambon Ralph, M. A., Patterson, K., Garrard, P., \& Hodges, J. R. (2003). Semantic dementia with category specificity: A comparative case-series study. Cognitive Neuropsychology, 20(3-6), 307-326.

Lambon Ralph, M. A., Sage, K., Jones, R. W., \& Mayberry, E.J.(2010). Coherent concepts are computed in the anterior temporal lobes. Proceedings of the National Academy of Sciences, 107(6), 2717-2722.

Luzzi, S., Snowden, J. S., Neary, D., Coccia, M., Provinciali, L., \& Lambon Ralph, M. A. (2007). Distinct patterns of olfactory impairment in Alzheimer's disease, semantic dementia, frontotemporal dementia, and corticobasal degeneration. Neuropsychologia, 45(8), 1823-1831.

Mahon, B. Z., \& Caramazza, A. (2009). Concepts and categories: A cognitive neuropsychological perspective. Annual Review of Psychology, 60, 27-51.

Martin, A. (2007). The representation of object concepts in the brain. Annual Review of Psychology, 58, 25-45.

Martin, A., \& Chao, L. L. (2001). Semantic memory and the brain: Structure and processes. Current Opinion in Neurobiology, 11, 194-201.

Martin, A., Wiggs, C. L., Ungerleider, L. G., \& Haxby, J. V. (1996). Neural correlates of category-specific knowledge. Nature, 379(6566), 649-652.

Mayberry, E. J., Sage, K., Ehsan, S., \& Lambon Ralph, M. A. (submitted). Relearning in semantic dementia reflects contributions from both medial temporal lobe episodic and degraded neocortical semantic systems: Evidence in support of the complementary learning systems theory.

McClelland, J. L., McNaughton, B. L., \& O' Reilly, R. C. (1995). Why There Are Complementary Learning-Systems in the Hippocampus and Neocortex - Insights from the Successes and Failures of Connectionist Models of Learning and Memory. Psychological Review, 102(3), 419-457.

Medin, D. L., Lynch, E. B., Coley, J. D., \& Atran, S. (1997). Categorization and reasoning among tree experts: Do all roads lead to Rome? Cognitive Psychology, 32, 49-96.

Mion, M. Patterson, K., Acosta-Cabronero, J., Pengas, G., Izquierdo-Garcia, D., Hong, Y. T., et al. (2010). What the left and right anterior fusiform gyri tell us about semantic memory. Brain.

Moore, C. J., \& Price, C. (1999). A functional neuroimaging study of the variables that generate category-specific object processing differences. Brain, 112, 943-962.

Mummery, C. J., Patterson, K., Price, C. J., Ashburner, J., Frackowiak, R. S. J., \& Hodges, J. R. (2000). A voxel-based morphometry study of semantic dementia: Relationship between temporal lobe atrophy and semantic memory. Annals of Neurology, 47(1), 36-45.

Nestor, P. J., Fryer, T. D., \& Hodges, J. R. (2006). Declarative memory impairments in Alzheimer's disease and semantic dementia. Neuroimage, 30(3), 1010-1020.

Omar, R., Hailstone, J. C., Warren, J. E., Crutch, S. J., \& Warren, J. D. (2010). The cognitive organization of music knowledge: A critical analysis. Brain, 133, 1200-1213.

Patterson, K., Nestor, P. J., \& Rogers, T. T. (2007). Where do you know what you know? The representation of semantic knowledge in the human brain. Nature Reviews Neuroscience, 8, 976-987.

Perani, D., Schnur, T., Tettamanti, C., Gorno-Tempini, M., Cappa, S. F., \& Fazio, F. (1999). Word and picture matching: A PET study of semantic category effects. Neuropsychologia, 37(3), 293-306.

Pobric, G., Jefferies, E., \& Lambon Ralph, M. A. (2010). Category-specific versus category-general semantic impairment induced by transcranial magnetic stimulation. Current Biology, 20, 964-968.

Pulvermuller, F. (2005). Brain mechanisms linking language and action. Nature Reviews Neuroscience, 6, 576-582.
Raven, J. C. (1962). Coloured progressive matrices sets $A, A B$, $B$. London: $H$. K. Lewis. Robinson, G., \& Cipolotti, L. (2001). The selective preservation of colour naming in semantic dementia. Neurocase, 7, 65-75.

Rogers, T. T., Lambon Ralph, M. A., Garrard, P., Bozeat, S., McClelland, J. L., Hodges, J. R., et al. (2004). Structure and deterioration of semantic memory: A neuropsychological and computational investigation. Psychological Review, 111(1) 205-235.

Rogers, T. T., \& McClelland, J. L. (2004). Semantic cognition: A parallel distributed processing approach. Cambridge, Massachusetts: MIT Press.

Rumelhart, D. E., \& Todd, P. M. (1993). Learning and connectionist representations. In D. E. Meyer, \& S. Kornblum (Eds.), Attention and performance XIV: Synergies in experimental psychology, artificial intelligence and cognitive neuroscience. Cambridge, MA: MIT Press.

Shallice, T. (1988). From neuropsychology to mental structure. Cambridge: Cambridge University Press.

Snowden, J., Griffiths, H., \& Neary, D. (1994). Semantic dementia: Autobiographical contribution to preservation of meaning. Cognitive Neuropsychology, 11(3) 265-288.

Snowden, J. S., Goulding, P. J., \& Neary, D. (1989). Sementic dementia: A form of circumscribed cerebral atrophy. Behavioural Neurology, 2, 167-182.

Snowden, J. S., Griffiths, H. L., \& Neary, D. (1995). Autobiographical experience and word meaning. Memory, 3(3-4), 225-246.

Snowden, J. S., Griffiths, H. L., \& Neary, D. (1996). Semantic-episodic memory interactions in semantic dementia: Implications for retrograde memory function. Cognitive Neuropsychology, 13(8), 1101-1137.

Snowden, J. S., \& Neary, D. (2002). Relearning of verbal labels in semantic dementia. Neuropsychologia, 40(10), 1715-1728. doi:10.1016/S0028-3932(02)00031-3

Snowdon, D. A., Lemper, S. J., Mortimer, J. A., Greiner, L. H., Wekstein, D. R., \& Markes bery, W. R. (1996). Linguistic ability in early life and cognitive function and Alzheimer's disease in late life: Findings from the Nun study. Journal of the American Medical Association, 275, 528-532.

Tanaka, J. \& Taylor, M. (1991). Object categories and expertise: Is the basic level in the eye of the beholder? Cognitive Psychology, 23, 457-482.

Thompson, S. A., Graham, K. S., Patterson, K., Sahakian, B. J., \& Hodges, J. R. (2002). Is knowledge of famous people disproportionately impaired in patient with early and questionable Alzheimer's disease? Neuropsychology, 16(3), 344-358.

Tranel, D., Damasio, H., \& Damasio, A. (1997). A neural basis for the retrieval of conceptual knowledge. Neuropsychologia, 35, 1319-1327.

Vitali, P., Abutalebi, J., Tettamanti, M., Rowe, J., Scifo, P., Fazio, F., et al. (2005). Generating animal and tool names: An fMRI study of effective connectivity. Brain and Language, 93, 32-45.

Warrington, E. K., \& James, M. (1991). The visual object and space perception battery. Bury St. Edmunds, Suffolk: Thames Valley Test Company.

Warrington, E. K., \& McCarthy, R. A. (1987). Categories of knowledge: Further fractionations and an attempted integration. Brain, 110, 1273-1296.

Warrington, E. K., \& Shallice, T. (1984). Category specific semantic impairments Brain, 107, 829-854.

Wilson, R. S., Mendes de Leon, C. F., Barnes, L. L., Schneider, J. A., Bienias, J. L, Evans, D. A., et al. (2002). Participation in cognitively stimulating activities and risk of incident Alzheimer disease. Journal of the American Medical Association, 287, $742-748$.

Woollams, A. M., Cooper-Pye, E., Hodges, J. R., \& Patterson, K. (2008). Anomia: A doubly typical signature of semantic dementia. Neuropsychologia, 46(10), 2503-2514. doi:10.1016/j.neuropsychologia.2008.04.005 